\title{
Insulin Dependent Diabetes: A Comparison of Families with Single and Multiple Affected Siblings
}

\author{
M. A. Jaworski, E. Colle, R. D. Guttmann, M. M. Belmonte, B. Taylor, M. P. Crepeau, J. Wilkins, \\ and R. Poirier \\ Montreal Children's Hospital - McGill University Research Institute, The Transplantation Service, Royal Victoria Hospital, \\ and Hôpital Sainte-Justine, Montreal, Quebec, Canada
}

\begin{abstract}
Summary. Families $(\mathrm{n}=14)$ with more than 1 sibling with insulin dependent diabetes were matched with families of similar size and age distribution containing only 1 affected child. The distribution of HLA haplotypes, age of onset of disease, and seasonal onset of disease were compared in the two groups. The data are not consistent with the hypothesis of a single autosomal recessive gene linked to the HLA region. The data do not permit a choice between other current hypotheses although they are compatible with the theory of 2 genes linked to the HLA region, acting additively, and requiring interaction either with environmental factors or other disease susceptibility genes. Diabetic children in the multiplex and simplex families did not differ in the month of onset of symptoms nor in the age at diagnosis although three multiplex pedigrees in which diabetes developed in all affected children before the age of 6 years were identified.
\end{abstract}

Key words: Insulin dependent diabetes, HLA typing, genetics of diabetes.

The mode(s) of inheritance of diabetes mellitus continue to perplex investigators. Genetic heterogeneity is manifest in the variety of diabetic syndromes in animal models [1], in the multiplicity of genetic syndromes associated with human diabetes [2], and in the delineation of familial patterns of both mild, noninsulin dependent $[3,4]$, and severe, insulin dependent diabetes (IDD) of the juvenile onset type. On the other hand, proposals for a single homogeneous mode of inheritance, including autosomal recessive inheritance with $50 \%$ penetrance, for all cases of IDD have been advanced [5].
Population studies of patients with IDD have shown an association between IDD and certain B antigens (B8, 18 and $15 \mathrm{Bw62})$ and $\mathrm{D} / \mathrm{DR}$ antigens (Dw3, Dw4, DR3, DR4), especially in Caucasian populations [6]. Studies $[6,7,8]$ have shown that in families with more than one affected sibling, there is a significant excess of shared HLA haplotypes among affected offspring. These groups, however, find a significant number (up to $45 \%$ ) of affected siblings who differ by at least one HLA haplotype from the proband, a finding difficult to reconcile with a hypothesis of simple HLA-linked recessive inheritance.

Similar studies in families containing only one diabetic child are limited [8]. Such families account for most cases of IDD ( $94 \%$ in our population). We have therefore compared two groups of families similar in all respects except for the presence of either one (simplex) or more than one (multiplex) insulin dependent diabetic.

\section{Materials and Methods}

\section{Clinical Material}

The population from which these families were chosen has been described in detail elsewhere [9]. All are Caucasian of European extraction, predominantly French Canadian and British, with important minorities of Italian and Jewish backgrounds. In this population, the mean annual incidence of IDD in children 17 years of age or less is $8.8 / 100,000$ for the years 1971 through 1978. During these years 588 diabetics in 581 families were identified. Of the 581 families, $544(94 \%)$ have only 1 affected child and 37 families $(6 \%)$ have two or more affected offspring. There were 1168 siblings of the diabetic probands in these families of whom 57 were diabetic $(5.0 \%)$

Fourteen inultiplex families were selected on the basis of their availability and willingness to participate. After selection of a multiplex family, the next family appearing for a routine visit in whom the number of siblings of similar age (matched within 5 year inter- 
Table 1. Haplotype segregation of sibling pairs

\begin{tabular}{|c|c|c|c|c|c|}
\hline & \multirow[t]{2}{*}{$\mathrm{Dm} / \mathrm{Dm}$} & \multicolumn{2}{|c|}{$\mathrm{Dm} /$ nonDm } & \multicolumn{2}{|c|}{ nonDm/nonDm } \\
\hline & & $\begin{array}{l}\text { Multi- } \\
\text { plex }\end{array}$ & $\begin{array}{l}\text { Sim- } \\
\text { plex }\end{array}$ & $\begin{array}{l}\text { Multi- } \\
\text { plex }\end{array}$ & $\begin{array}{l}\text { Sim- } \\
\text { plex }\end{array}$ \\
\hline \multicolumn{6}{|l|}{ Sharing } \\
\hline $\begin{array}{l}2 \text { haplotypes } \\
\text { Sharing }\end{array}$ & 14 & 7 & 10 & 3 & 6 \\
\hline $\begin{array}{l}1 \text { haplotype } \\
\text { Sharing }\end{array}$ & 3 & 10 & 12 & 5 & 11 \\
\hline 0 haplotype & 1 & 9 & 8 & 3 & 5 \\
\hline
\end{tabular}

vals) and whose ethnic origin and family history most closely matched that of the multiplex family was asked to participate. Families were not matched for the age or season of onset of diabetes. No parent in either group had IDD. Probands were less than 17 years of age at the time of diagnosis with one exception. Mean age at diagnosis of the proband in the multiplex families was $8.3 \pm 1.6$ years, of the affected siblings in the multiplex families $11.3 \pm 1.1$ years $(9.8 \pm 1.0$ for all diabetics in the multiplex families), and of the probands in the simplex families $9.6 \pm 1.1$ years. The duration of diabetes in the probands was $8.5 \pm 1.1$ years in the multiplex families and $6.0 \pm 1.5$ in the simplex families. The mean age of all offspring at the time of study was 16.5 years in multiplex and 16.8 years in simplex families with the mean age of the unaffected siblings $18.3 \pm 1.9$ and $18.4 \pm 1.1$ years respectively. In the simplex families the mean age of HLA identical siblings was $17.8 \pm 1.8$ years. Both simplex and multiplex families had an average of 3.2 children. Pedigrees for 4 generations were obtained with respect to type of glucose intolerance (including maternal gestational glycosuria), age of onset, treatment and complications of diabetes and occurrence of other endocrine and autoimmune diseases. (Complete data can be obtained from the authors on request.)

\section{Tissue Typing Methods}

HLA typing for antigens at the A, B, C and DR loci was performed according to the standard microcytotoxicity method of Terasaki [10], using UCLA research trays. The method previously described from this laboratory was used for mixed lymphocyte culture reactions [11]. Twenty specificities were tested at the A locus, 31 at the B locus, and 5 at the $C$ locus. All diabetic offspring $(n=44)$ and $45 / 46$ normal siblings as well as all living parents $(n=$ 44 ) were typed. Controls were 263 primiparous women from the same metropolitan area.

\section{Results}

\section{Haplotype Segregation (Table 1)}

There were 16 diabetic siblings in the multiplex families. Thirteen shared both haplotypes with the proband, 2 shared 1, and 1 was discordant. Among non-diabetic siblings there were 3 HLA identical, 6 haploidentical and 3 discordant in the multiplex families and 10 HLA identical, 12 haploidentical and 8 discordant in the simplex families. Haplotype segregation in sibling pairs is shown in Table 1 . A non-random assortment of haplotypes was found among diabetic pairs in the multiplex families. The method of Green and Woodrow [12] was used to test the null hypothesis of random assortment of haplotypes among diabetic pairs versus the alternative hypothesis that there is a disturbance of zygotic assortment which causes the number of "repeats" (that is sibling pairs sharing 1 or 2 haplotypes) to be larger than expected. By this method the null hypothesis could be rejected at the level of $p<0.001$. On the other hand, the assortment of haplotypes among the non-diabetic siblings in both families was not different from that predicted by random zygotic assortment.

In the multiplex families 3 non-diabetic siblings share 2 haplotypes with the proband and 6 nondiabetic siblings share 1 haplotype. The HLA identical siblings in family M5 are also identical by virtue of a negative mixed lymphocyte culture (MLC) reaction. In families M9 and M14 the identical siblings share the same D antigen. In family M10 siblings 1 and 2 are identical, sibling 3 who shares only 1 haplotype with 1 and 2, is MLC discordant with the other two. Diabetic siblings in families M11 and 12 who share only one or no haplotypes with diabetic probands are not MLC identical. Therefore, recombination between $A, B$, and D loci cannot explain the discordance between the presence of diabetes and the lack of HLA identity. In the simplex families there are 10 siblings sharing 2 and 12 sharing 1 haplotype who are not diabetic.

\section{HLA Antigen Frequency among Offspring}

(Table 2)

The frequency of those antigens at the B locus which had been found to be significantly different from a local control population in a large group of IDD were examined in the two groups. When $p$ values were corrected for number of antigens, the only significant differences between the groups was in the frequency of B7, although the small numbers may have masked other less obvious differences. In the multiplex families, no diabetic children expressed the B7 antigen. In simplex families, the frequency of B8 was increased among both the diabetic and non-diabetic offspring, but this was not statistically significant. The slight increase in B15 among the diabetic offspring of the simplex families was not statistically significant, nor was the decrease in B7. Among the normal siblings the frequency of $\mathrm{B} 7$ was almost double that of the control population. No diabetic offspring in either group were homozygous for B8 or B15. There were $2 \mathrm{HLA}$ identical sibling pairs who were $\mathrm{B} 18 / \mathrm{B} 15$ heterozygotes in the multiplex families. The frequency of B18/B15 heterozygotes among multi- 
Table 2. Frequency of B antigens

\begin{tabular}{llllllll}
\hline Group & $\begin{array}{l}\text { No. of } \\
\text { patients }\end{array}$ & B8 & B15 & B18 & B7 & B8/B15 & B18/B15 \\
\hline Control & 263 & 0.118 & 0.076 & 0.118 & 0.190 & 0.0038 & 0.0038 \\
$\begin{array}{l}\text { New cases IDD } \\
\text { Montreal }\end{array}$ & & & & & & & \\
Aug. 1976-Dec. 1978 & 155 & $0.290^{*+}$ & $0.265^{*+}$ & 0.188 & 0.090 & $0.026^{\mathrm{a}}$ & $0.045^{\mathrm{b} *+}$ \\
$\quad \begin{array}{l}\text { Multiplex } \\
\quad \text { Diabetics }\end{array}$ & 30 & 0.166 & $0.233^{*}$ & 0.166 & $0.000^{*}$ & 0.000 & $0.130^{*+}$ \\
$\quad$ Non-diabetics & 14 & 0.070 & 0.000 & 0.140 & 0.140 & 0.000 & 0.000 \\
$\quad \begin{array}{l}\text { Simplex } \\
\quad \text { Diabetics }\end{array}$ & 14 & 0.285 & 0.214 & 0.140 & 0.140 & 0.07 & 0.07 \\
$\quad$ Non-abetics & 30 & 0.266 & 0.070 & 0.070 & 0.330 & 0.000 & 0.000 \\
\hline
\end{tabular}

a One included in simplex family group

b Two included in multiplex family and one in simplex family group

${ }^{*} \mathrm{p}=<0.01$, vs control

${ }^{+} \mathrm{p}=<0.05$, corrected for number of antigens, vs control

plex diabetic siblings was significantly increased above that of the control population $(\mathrm{p}<0.001)$. In the simplex families there was $1 \mathrm{~B} 8 / \mathrm{B} 15$ and $1 \mathrm{~B} 18 /$ B15 heterozygote; neither of these children had an HLA identical sibling.

\section{Epidemiology and Family History}

There was no difference in the mean age at onset of the disease in the two groups, nor in the proportion of children diagnosed at a young age ( $<6$ years). There was no statistical difference in the seasonal occurrence of cases between the two groups, although there were proportionately more autumn cases in the multiplex group.

The distribution of $\mathrm{B}$ antigens among the parents in the two groups was not statistically different from that of the control population. Three pedigrees have a history of IDD in second degree relatives. There are pedigrees containing several generations of maturity onset diabetes in both groups.

\section{Discussion}

Data on two groups of closely matched families is presented, which show the previously described [7, 13] non-random assortment of haplotypes found in the diabetic siblings of the proband in the multiplex families and the normal distribution of haplotypes in nonaffected siblings in simplex and multiplex families. There was no decrease in the number of unaffected siblings sharing 2 haplotypes as suggested by Bengsch [8], whose study population differs from ours in that the proband was diagnosed at $<30$ years rather than $<17$ years and no attempt was made to match numbers or ages of siblings. Eighteen percent of affected siblings in our group of multiplex families are not HLA identical with the proband. In the simplex families 10 children are HLA identical (mean age 17.8 years) but have not yet developed the disease. This is past the age of peak incidence of IDD $[10,17]$, although a second smaller peak during the third decade has been reported in some studies $[7$, 17]. Finally, our prevalence figures for diabetes in siblings of IDD $(5.0 \%)$ agrees with figures cited by Christy et al. [13] and Krawisz [18] and is well below the $12.5 \%$ required for the hypothesis proposing a single autosomal recessive gene with $50 \%$ penetrance.

A second hypothesis proposes two susceptibility genes linked to the HLA region with expression depending on environmental interaction and/or other genes not HLA linked. It has been suggested [13] that the 2 genes are linked to Dw3 and Dw4 antigens and secondarily to the $\mathrm{B}$ antigens in linkage disequilibrium with these $\mathrm{D}$ antigens. Individuals heterozygous for Dw3/Dw4 have a higher relative risk than either the Dw3 or Dw4 homo- or hemizygote [13]. Linkage disequilibrium of B8 and of B18 with DR3 and of B15 (Bw62) with DR4 [14, 15, 16] have been demonstrated in some populations, and account for the increased susceptibility of B8/B15 and B18/B15 heterozygotes in these groups. This hypothesis permits both the increased numbers of HLA identical siblings as well as the affected siblings sharing only 1 haplotype with the proband as found in the multiplex families in this study. There are 2 siblings pairs in the multiplex families in which the affected siblings share B18/B15. In the simplex group there is one child with $\mathrm{B} 8 / \mathrm{B} 15$ and one with $\mathrm{B} 18 / \mathrm{B} 15$; neither has an HLA identical sibling at risk, although 
partial DR typing of these families confirms the increased frequency of DR3 and DR4. Nine multiplex families have been typed. In three the diabetic siblings are DR3/DR4, in two the proband is DR3/ DR4 and the second diabetic is DR4, and in two the diabetic pairs type DR4 only. Five simplex families have been typed; four probands are DR4 only, and the B8/B15 heterozygote is DR3/DR4. Thus our findings are compatible with and favour the 2 gene overdominant theory of Christy et al. [13].

As in other reports $[13,8]$, the frequency of $B 7$ is decreased in the affected children in the multiplex but not the simplex families. There is, however, an increase in the frequency of B7 in the unaffected members of simplex families.

We cannot draw any conclusions about the environmental trigger. Simultaneous environmental insults to affected siblings in the multiplex families are, however, rare. The mean interval between diagnosis in proband and in affected sibling(s) (4.5 years) is similar to that in pairs of HLA identical siblings in multiplex families [6]. The longest interval was 13 years. Often the second affected sib was not yet born when the proband was diagnosed. Only in a minority of families $(3 / 14)$ were pairs of siblings diagnosed within 2 years of each other.

The mean age of onset of diabetes was the same in the simplex and multiplex families. However, seven children from three multiplex families accounted for almost half of all the children whose diabetes occurred before 6 years of age. This suggests a familial predisposition to early islet cell failure in some families. In these three pedigrees all affected sibs shared at least 1 HLA haplotype, there was a family history of diabetes and the interval between diagnosis was 2-13 years. Suarez and colleagues [19] have recently put forward a theory concerning a major susceptibility gene for IDD not in linkage with the HLA region while genes associated with the HLA region confer increased or decreased expressivity. Such a susceptibility gene might govern mechanisms involved in the ability of the beta cell to undergo hyperplastic or hypertrophic growth following injury or during periods of rapid growth such as puberty.

Acknowledgements. Supported by grants from the National Health and Welfare of Canada and the Diabetic Children's Foundation, Montreal.

\section{References}

1. Like AA (1977) Spontaneous diabetes in animals. In: Volk BW, Wellmann KR (eds) The diabetic pancreas. Plenum Press, New York, p 381-421
2. Rimoin DL (1976) Genetic syndromes associated with glucose intolerance. In: Creutzfeldt W, Köbberling J, Neel JV (eds) The genetics of diabetes mellitus. Springer, Berlin Heidelberg New York, p 43-63

3. Tattersall RB, Fajans SS (1975) A difference between the inheritance of classical juvenile-onset and maturity onset type diabetes of young people. Diabetes 24: 44-53

4. Barbosa J, Ramsay R, Goetz FC (1978) HLA in maturity onset hyperglycemia in the young. Arch Intern Med 138: 90-93

5. Rubinstein P, Suciu-Foca N, Nicholson F (1977) Genetics of juvenile diabetes mellitus, a recessive gene closely linked to HLA D and with $50 \%$ penetrance. N Engl J Med 297: 1036-1040

6. Barbosa J, King R, Noreen H, Yunis EJ (1977) The histocompatibility (HLA) system in juvenile insulin dependent diabetic multiplex kindreds. J Clin Invest 60: 989-998

7. Cudworth AG (1978) Type I diabetes. Diabetologia 14: 281-291

8. Bengsh N, Köbberling J, Eckert G, Willms B (1978) HLA typing in juvenile diabetics with and without positive family history and in families with one or two diabetic siblings. Diabetologia 15: 447-451

9. West R, Belmonte MM, Colle E, Crepeau MP, Wilkins J, Poirier R (1979) Epidemiologic survey of juvenile onset diabetes in Montreal. Diabetes 28: 690-693

10. Mittal KK, Mickey MR, Singal DP, Terasaki PI (1968) Serotyping for homotransplantation: Refinement of microdroplet lymphocyte cytotoxicity test. Transplantation 6: 913-927

11. Boylston AW, Guttmann RD, Merrill GP (1968) A simplified method for the quantitation of in vitro leucocyte culture. Int Arch Allergy Appl Immunol 34: 339

12. Green JR, Woodrow JC (1977) Sibling method for detecting HLA-linked genes in disease. Tissue Antigens 9: 31-35

13. Christy M, Green A, Christau B, Kranman M, Nerup J, Platz P, Thomsen M, Ryde L, Svejgaard A (1978) Studies of the HLA system and insulin dependent diabetes. Diabetes Care 2: 209-214

14. Svejgaard A, Platz R, Ryder LP, Stau ML, Thomsen M (1975) HLA and disease association; a survey. Transplant Rev 22: 3-43

15. Farid NR, Sampson L, Barnard JM, Davis AJ, Hillman DA (1979) HLA-D-related (DR4) antigens in juvenile diabetes mellitus. Diabetes 28: 522-557

16. Solow H, Hidalgo R, Singal DP (1979) Juvenile onset diabetes: HLA-A, -B, $-\mathrm{C}$ and Dr alloantigens. Diabetes 28: 1-4

17. Christau B, Kromann H, Andersen OO, Christy M, Buschard K, Arnung K, Kristensen IH, Peitersen B, Steinrud J, Nerup J (1979) Incidence, seasonal and geographical patterns of juvenile-onset insulin dependent diabetes mellitus in Denmark. Diabetologia 13: 281-284

18. Krawisz J, Palumbo P, Taswell H, Elvback L (1978) HLA antigens in patients with juvenile diabetes and their first degree relatives. Mayo Clin Proc 53: 782-787

19. Suarez B, Hodge SE, Reich T (1979) Is juvenile diabetes determined by a single gene closely linked to HLA? Diabetes 28: $527-532$

Received: October 1, 1979,

and in revised form: March 3, 1980

Dr. E. Colle

Montreal Childrens Hospital

2300 Tupper Street

Montreal, Quebec H3H 1P3

Canada 